\title{
THE LUNG VOLUME IN HYPERKINETIC STATES
}

BY

\author{
D. G. B. RICHARDS, A. G. W. WHITFIELD, W. M. ARNOTT, AND \\ J. A. H. WATERHOUSE
}

From the Departments of Medicine and Medical Statistics, Queen Elizabeth Hospital, University of Birmingham

Received February 1, 1952

Previous publications from this department have defined the normal range of the total lung volume and its subdivisions (Whitfield et al., $1950 a, b, \& c$ ) and the changes that take place in low output cardiac syndromes (Richards et al., 1951). The present paper describes the results of study of the lung volume in hyperkinetic states.

The subjects selected for this investigation were patients suffering from anæmia or hyperthyroidism. Sharpey-Schafer $(1944,1945)$ and Brannon et al. (1945) have shown that in anæmic states the cardiac output is raised and similar changes were demonstrated in hyperthyroid subjects by Davies et al. (1924), Liljestrand and Stenstrom (1925-26), Robinson (1926), Burwell et al. (1929), Fullerton and Harrop (1930), Boothby and Rynearson (1935), and Gladstone (1936). The cardiac output of a small group of hyperthyroid subjects has been determined by cardiac catheterization in this department and in each case it has been found to be grossly elevated. Davies et al. (1924), Fullerton and Harrop (1930), and Boothby and Rynearson (1935) also showed that in hyperthyroidism the cardiac output returned to normal as the basal metabolic rate decreased following partial thyroidectomy.

Rabinowitch (1923) determined the vital capacity in nearly 200 patients suffering from hyperthyroidism and found that it diminished as the basal metabolic rate increased. With rates of plus 90-100 per cent the vital capacity fell to 42 per cent of its normal while with lower rates (plus 20$30 \%$ ) the vital capacity was 79 per cent of its normal. Peabody and Wentworth (1917) found slight diminution in the vital capacity of 7 patients suffering from hyperthyroidism and 13 cases of anæmia. Lemon and Moersch (1924) found the vital capacity often reduced in hyperthyroidism but the reduction was unrelated to the degree of thyrotoxicosis.

Patients suffering from emphysema have not been included in this study because of the changes in lung volume associated with that disorder.

\section{Methods AND Results}

The vital capacity and its two components the complemental and reserve air were measured in the usual way on a Benedict-Knipping spirometer. The functional residual air, and from it the residual air, was determined by the closed circuit constant volume hydrogen (or helium) dilution method described by McMichael (1939).

Ten patients suffering from hyperthyroidism were studied before treatment and again when their basal metabolic rate had returned to normal following partial thyroidectomy. The results obtained are summarized in Table I. The lung volume of nine cases of anæmia was also determined before treatment and again either after normal blood levels had been restored or a substantial improvement in their hæmatological state had been attained. The results are shown in Table II. Of the anæmic subjects three were suffering from pernicious anæmia, two from melæna due to peptic ulcer, two from anæmia due to uterine hæmorrhage, one from thrombocytopenic purpura, and one from macrocytic anæmia following jejuno-colostomy. 
A statistical analysis of the findings in the ten thyrotoxic and nine anæmic subjects considered as one group is shown in Table III.

A striking parallelism will be seen between the hyperthyroid and anæmic subjects both showing before treatment an increase of $200-400 \mathrm{ml}$. in the functional residual air and residual air and a reduction of 200-300 ml. in the vital capacity and complemental air, the reserve air and total lung volume remaining virtually unchanged. Owing, however, to the relatively small numbers in each group these changes do not attain any high degree of statistical significance until all the subjects are considered together (Table III). The justification for grouping them together is the well founded assumption that before treatment they are both hyperkinæmic while after treatment their cardiac output is normal.

TABLE I

Mean Differences in Lung Volume of 10 Thyrotoxic Subjects before and after Thyroidectomy

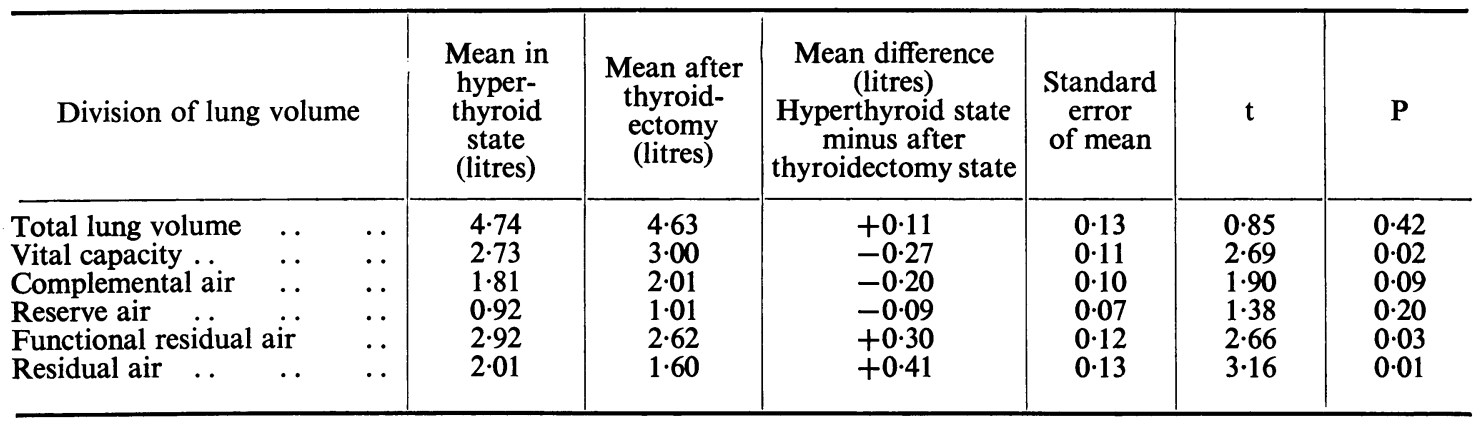

TABLE II

Mean Differences in Lung Volume of Nine Anemic Subjects before and after Effective Treatment

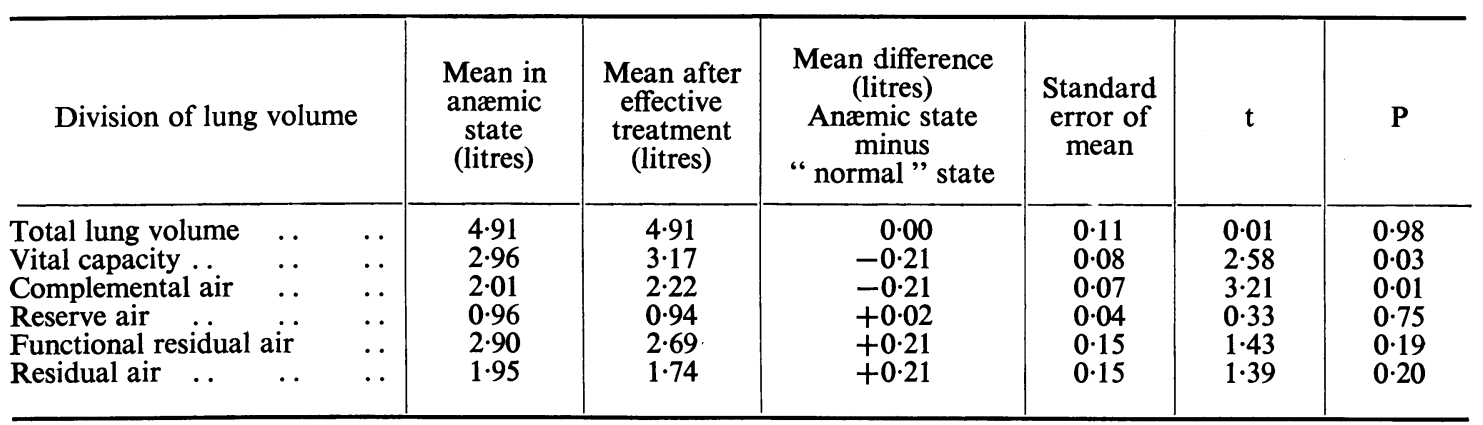

TABLE III

Mean Differences in Lung Volume of 9 Anamic and 10 Thyrotoxic Subjects before and after TREATMENT

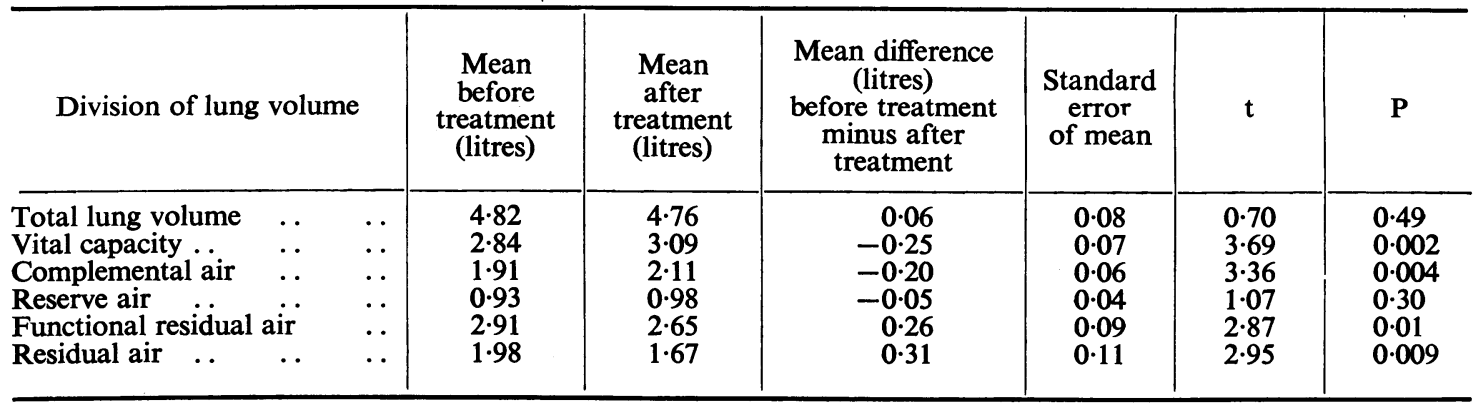


An attempt was next made to ascertain to what extent these changes were correlated with the degree of anæmia as measured by the hæmoglobin percentage and the severity of thyrotoxicosis as indicated by the basal metabolic rate. The correlation coefficients obtained are shown in Tables IV and V from which it will be seen that in the thyrotoxic group the vital capacity and complemental air changes show no correlation and the functional residual air and residual air changes only a statistically insignificant positive correlation with the basal metabolic rate changes. Such a finding is hardly surprising and serves to confirm the impression that the degree of elevation of the basal metabolic rate above normal does not always agree with the severity of the thyrotoxicosis as judged clinically. In the anæmic group, however, there are positive correlation coefficients between the vital capacity and complemental air changes and the hæmoglobin percentage changes and negative correlation coefficients between the changes in the functional residual air and residual air and the hæmoglobin percentage change, all of which are statistically significant except in the case of the functional residual air.

TABLE IV

Correlation Coefficients between lung Volume Changes and Basal Metabolic Rate Changes in HYPERTHYROID SUBJECTS

\begin{tabular}{|c|c|c|c|c|c|c|}
\hline Total lung volume & $\cdots$ & * & $\ddot{*}$ & $\cdots$ & . & $\begin{array}{r}+0.47 \\
+0.03\end{array}$ \\
\hline Vital capacity $\ddot{\text {. }}$ & .. & $\cdots$ & . & $\cdots$ & .. & $\begin{array}{l}+0.03 \\
-0.05\end{array}$ \\
\hline Complemental air & $\cdots$ & . & .. & $\cdots$ & $\cdots$ & $\begin{array}{l}-0.05 \\
+0.11\end{array}$ \\
\hline Reserve air & & . & - & $\cdots$ & - & $\begin{array}{l}+0 \\
+0 .\end{array}$ \\
\hline Functional residual air & & . & .. & $\cdots$ & . & $\begin{array}{l}+0 \\
+0\end{array}$ \\
\hline Residual air & $\cdots$ & .. & .. & . & & +0 \\
\hline Significance levels & $\begin{array}{r}0.63 \\
0.72\end{array}$ & . & .. & $\cdots$ & & $2 \%$ \\
\hline & 0.76 & .. & .. & .. & .. & $\%$ \\
\hline
\end{tabular}

TABLE V

Correlation Cofficients between lung Volume Changes and Hæmoglobin Percentage Change in ANAMIC SUBJECTS

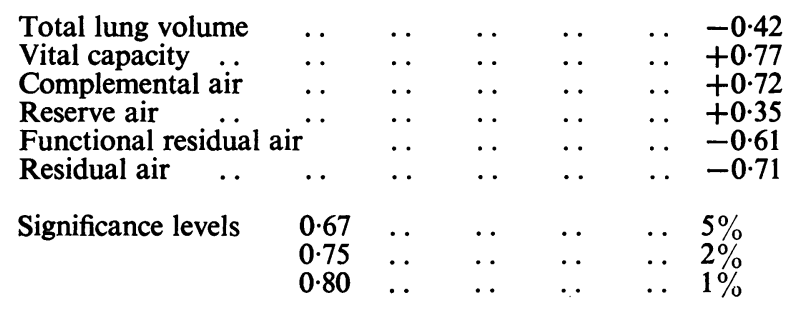

\section{Discussion}

It is clear that in anæmia and thyrotoxicosis the vital capacity and complemental air are diminished and the functional residual air and residual air are increased, and in anæmic subjects these changes are correlated with the severity of the anæmia. The next question is what mechanism is responsible for these changes. It is natural to presume that the high cardiac output is responsible and in an endeavour to confirm this we determined the vital capacity before and after severe exercise in a series of ten normal subjects. There was no diminution after exercise except during the first $2 \frac{1}{2}-5$ minutes when dyspnœa and tachypnœa seemed undoubtedly responsible, and the transient increase in cardiac output associated with exercise does not appear to produce the diminution in vital capacity that is associated with the sustained hyperkinæmia of hyperthyroidism and anæmia.

In a previous publication (Richards et al., 1951) we have shown that very similar lung volume changes occur in fully compensated " low-output " cardiacs such as the subjects of chronic rheumatic or hypertensive heart disease or coronary artery disease, and it is tempting to presume that in both 
groups an increased volume of blood in the pulmonary circulation producing a stiff lung (lungenstarre) is responsible. However, Borden et al. (1949) have shown that in fully compensated mitral stenosis the volume of blood in the lungs is not increased and such an explanation is therefore open to doubt. Furthermore, though in hyperthyroidism the total blood volume is increased (Chang, 1931; Gibson and Harris, 1939) in anæmia it is reduced (Sharpey-Schafer, 1944, 1945), and it is difficult to believe that exactly the same lung volume changes could be produced by an increase in the volume of blood in the pulmonary circulation in two groups whose total blood volume differs in this way. It may be that prolonged hyperkinæmia produces an increase in the tissue fluid in the lungs (lungenschwellung) and that this is the responsible mechanism, but such an hypothesis seems quite impossible of proof.

All that can be said with certainty is that ventilatory efficiency is impaired in anæmia and thyrotoxicosis. How such impairment comes about is not understood.

\section{SUMMARY}

The total lung volume and all its subdivisions have been determined in ten patients suffering from hyperthyroidism and nine patients with anæmia before and after effective treatment.

In hyperthyroidism and anæmia the vital capacity and complemental air are reduced and the functional residual air and residual air are increased. The total lung volume and reserve air are unchanged.

The mechanism underlying these changes is not understood and there is good reason to suppose that "lungenstarre" is not responsible.

In anæmic subjects the lung volume changes are closely correlated with the hæmoglobin percentage.

We are indebted to Professor Lancelot Hogben, F.R.S., for placing the facilities of his department at our disposal, to Miss Gwenda Griffith and Mr. A. C. Pincock for valuable technical assistance, and to Imperial Chemical Industries for a grant towards the expenses of this investigation.

\section{REFERENCES}

Boothby, W. M., and Rynearson, E. H. (1935). Arch. intern. Med., 55, 547.

Borden, C. W., Ebert, R. V., Wilson, R. H., and Wells, H. S. (1949). J. clin. Invest., $28,1138$.

Brannon, E. S., Merrill, A. J., Warren, J. V., and Stead, E. A. (1945). J. clin. Invest., $24,332$.

Burwell, C. S., Smith, W. C., and Neighbors, de W. (1929). Amer. J. med. Sci., 178, 157.

Chang, H. C. (1931). J. clin. Invest., 10, 475.

Davies, H. W., Meakins, J., and Sands, J. (1923-24). Heart, 11, 299.

Ebert, R. V., Borden, C. W., Wells, H. S., and Wilson, R. H. (1949). J. clin. Invest., 28, 1134.

Fullerton, C. W., and Harrop, G. A. (1930). Johns Hopk. Hosp. Bull., 46, 203.

Gibson, J. G., and Harris, A. W. (1939). J. clin. Invest., 18, 59.

Gladstone, S. A. (1936). Proc. Soc. exp. Biol., N.Y., 34, 587.

Lemon, W. S., and Moersch, H. J. (1924). Arch. intern. Med., 33, 136.

Liljestrand, G., and Stenstrom, N. (1925-26). Acta med. Scand., 63, 99.

McMichael, J. (1939). Clin. Sci., 4, 167.

Peabody, F. W., and Wentworth, J. A. (1917). Arch. intern. Med., 20, 443.

Rabinowitch, I. M. (1923). Arch. intern. Med., 31, 910.

Richards, D. G. B., Whitfield, A. G. W., Arnott, W. M., and Waterhouse, J. A. H. (1951). Brit. Heart J., 13, 381.

Robinson, G. C. (1926). J. Amer. med. Ass., 87, 314.

Sharpey-Schafer, E. P. (1944). Clin. Sci., 5, 125.

- (1945). Lancet, $2,296$.

Whitfield, A. G. W., Waterhouse, J. A. H., and Arnott, W. M. (1950, a). Brit. J. Soc. Med., 4, 1.

$(1950, b)$. Brit. J. Soc. Med., 4, 86

$(1950$, c). Brit. J. Soc. Med., 4, 113. 